\section{Quality Assurance and Use of PCR in Clinical Trials}

\section{Patricia S. Reichelderfer ${ }^{1}$} and J. Brooks Jackson ${ }^{2}$

\author{
${ }^{1}$ Division of AIDS, National \\ Institute of Allergy and Infectious \\ Diseases, National Institutes of \\ Health, Bethesda, Maryland 20892; \\ ${ }^{2}$ Institute of Pathology, Case \\ Western Reserve University and \\ University Hospitals of Cleveland, \\ Cleveland, Ohio 44106
}

Many assays are presently available for detecting and quantifying human immunodeficiency virus type 1 (HIV-1) in clinical trials. ${ }^{(1-3)}$ Some of these assays, quantitative peripheral blood and plasma microculture and HIV-1 p24 antigen measurement, have been standardized and included as part of an ongoing Quality Assurance Program (QAP) within the context of the AIDS Clinical Trials Group (ACTG). ${ }^{(2,4)}$ Recently, the PCR assay for detection of HIV-1 DNA has been added to the ACTG QAP. ${ }^{(5)}$ The exquisite sensitivity of the PCR techniques for detecting nucleic acid sequences makes it highly desirable for use in clinical trials both for early diagnosis and for the monitoring of patient response to therapy. However, the technical difficulties associated with PCR assays, as well as the number and variety of methods employed, necessitate the participation of sites in a QAP to have accurate and comparable results for a multicenter trial.

The value of any assay in a clinical trial, including PCR, cannot be simply based on its sensitivity, specificity, and reproducibility. Other factors, such as the ability of an assay to predict a specified clinical outcome, or an assay's response in relation to initiation of therapy and its correlation with outcome need to be considered. An assay may be highly sensitive, specific, inexpensive, and easy to perform, but of limited use diagnostically or in monitoring patients on therapy. In this respect, it is important to validate an assay's clinical utility before widespread use in clinical trials or clinical practice. In this paper we describe approaches for quality assurance for DNA and RNA PCR and what currently is known about the value of these assays for use in clinical trials.

\section{QUALITATIVE DNA PCR}

\section{Quality Assurance: General Considerations}

DNA PCR for detection of HIV-1 DNA in peripheral blood mononuclear cells (PBMC) has been used primarily for determining the infection status of infants born to HIV-1-infected mothers. ${ }^{(6-9)}$ Use of nonstandardized HIV-1 DNA PCR assays at multiple sites resulted in variable sensitivity and specificity. ${ }^{(10-}$ 13) Thus, the first step in establishing quality assurance was the utilization by all participating sites of commercial DNA PCR kits with standardized reagents and procedures, and use of a common algorithm for performing the procedure and interpreting the results. Diagnostic assays for HIV-1 must be highly sensitive, as well as highly specific, because the consequences of either a false-negative or a false-positive determination are great. Some general guidelines need to be followed to ensure adequate performance. Careful attention must be paid to specimen collection and processing. False-negative results can be obtained from specimens that are contaminated with inhibitors of Taq polymerase such as hemoglobin or heparin. ${ }^{(14)}$ False-positive results can be caused by "carryover" of previously amplified sequences if pre- and postamplification steps are performed in the same work area. ${ }^{(15)}$ Sample preparation should always be physically separated from performing the PCR reaction itself, and separate sets of supplies and pipetting devices should be dedicated to each part of the reaction. Similarly, controls for amplification (weak, yet consistently positive) should be run with each assay. Use of highconcentration controls will not give an indication of minimal detection limits and may result in contamination of other specimens in the run. The use of uracil- $N$-glycosylase $(\mathrm{UNG})^{(16)}$ has reduced the number of false positive results associated with carryover, but this method works only if all PCR reactions performed in the laboratory for a given template make use of the UNG protocol. The recent introduction of signature primer pairs that contain HIV-1 virus-specific sequences at the $3^{\prime}$ end and a nonhuman, nonviral se- 
quence at the $5^{\prime}$ end, which can then be subsequently used to differentiate true-positive from false-positive results. Target DNA is amplified using one of three sets of primer pairs: virus-specific primer, nonhuman-nonviral virusspecific primer, and nonhuman-nonviral primer. HIV-1-positive DNA will be detected with the first two primers but not the nonhuman-nonviral primer. HIV-1-negative DNA will not be detected by any of the primers. However, HIV-1-negative DNA that has positive carryover will be positive by all three primers (including the nonhuman-nonviral primer), indicating the presence of carryover contamination. Although this approach may be useful in the future, it has not been adapted commercially to date. ${ }^{(17)}$ Furthermore, none of the above strategies will prevent cross-contamination of samples or plasmid contamination. Thus, work area separation and meticulous laboratory practices cannot be overemphasized. This is particularly important for diagnostic testing, where the absolute amount is not important but exquisite sensitivity and specificity of the assay are paramount. Thus, the major focus of the DNA PCR QAP has been to ensure a high degree of sensitivity and specificity. The ACTG QAP for DNA PCR has been reported elsewhere. ${ }^{(5)}$ The following is a brief description of the program.

\section{Quality Assurance: ACTG Guidelines}

Laboratories are first assessed on their competency to perform the assay. Sites are expected to identify correctly as positive or negative a coded certification panel consisting of 30 cell pellets containing different HIV-1 proviral copy numbers $(0,2,5,10,20,50)$ and eight whole-blood samples. To identify a specimen as positive or negative, sites follow a specific testing algorithm where a single extraction is followed by a duplicate amplification. Detection is performed in singlet. Discordant results, one positive and negative, are resolved by performing either a third amplification and detection or an amplification/detection in duplicate on a second pellet. Known cell pellet standards are also provided. A site must have no false-positive results and must correctly identify as positive the 10-copy-number cell pellet to have an acceptable performance.

Following initial demonstration of competency, sites are required to undergo quarterly proficiency testing of eight whole-blood specimens. While proficiency testing monitors the performance of laboratory staff on a particular proficiency panel, it does not address the more critical issue of falsepositive and -negative results for any given run. ${ }^{(15)}$ To address this issue of real-time run validation, coded quality assurance (QA) pellets of 0 or $10 \mathrm{HIV}-1$ proviral copies per 125,000 PBMC are included with each run. Results for the QA pellets are entered into an encrypted computer file, which immediately assesses the validity of the run-no false-positive or false-negative results. In addition, for each run the following controls are included: (1) two extraction reagent controls; (2) two each of $0,2,5,10$, and 20 copy standards; and (3) one to three QA pellets. For a run to be valid, the 0-copy controls must be negative, the 10- and 20-copy standards must both be positive, and the QA pellets must be correct. To date, no erroneous values have been obtained from the encrypted samples. However, this approach will not identify falsepositive results because of contamination of the sample during specimen preparation, where specimen preparation and testing are performed at two distinct locations.

At the present time, 11 ACTG laboratories are participating in the QAP with four additional laboratories expected to join within the next few months. Of 11 laboratories, 9 use the Roche Amplicor kit (Roche Diagnostic Systems, Branchburg, NJ) for amplification and detection of HIV-1 gag sequences, and 2 of 11 laboratories use the Perkin-Elmer HIV-1 core amplification kit (Nor- 
walk, CT) and the GenProbe detection kit (San Diego, CA) for amplification and detection of HIV-1 gag sequences. The reproduciblity and relative sensitivity of the assay for the copy number standards in these laboratories are shown in Table 1 . The reproducibility of the assay for the $0,10,20$, and 50 copy numbers is $100 \%$. The reproducibility to date for the 2- and 5-copy number standards reflects the expected Poisson distribution for those lowercopy-number standards. The specificity for whole-blood specimens from seronegative patients is $100 \%$, and the sensitivity on whole-blood specimens from seropositive donors is $94 \%$. The false-negative results obtained were from duplicate aliquots of two samples that were found negative by quantitative micrococulture for $65 \%$ and $95 \%$ of the laboratories. Of the other seven false-negative results, six were derived from one laboratory on one run. On the basis of these results and to minimize costs, the quality control panel for each run has been modified. The new quality control panel consists of the following: (1) two each of the 0 - and 5-copy number standards; (2) one each of the 10-and 20-copy standard; and (3) two QA pellets for each 10 specimens assayed. As before, the 0-copy number control and QA pellets must be correct; however, assay sensitivity will be based on an absolute value for the 20-copy number standard of either $>2.0$ optical density for the Roche Amplicor EIA assay or $>50,000$ relative light units for the GenProbe chemiluminescence assay.

\section{Clinical Usage}

Serological diagnosis of HIV-1 infection in infants born of HIV-1-infected mothers is problematic because of the presence of maternal antibody for up to 15 months after birth. Several investigators have evaluated the utility of DNA PCR to diagnose infection in these infants. ${ }^{(18-20)}$ The combined sensitivity of the assay in these four studies was $94.5 \%$. However, sensitivity varies with age of the infant ${ }^{(8,18,19)}$ and can be primer-pair dependent. ${ }^{(18)}$ The overall specificity of the assay was $98.5 \%$. Two laboratories reported PCR-positive samples on uninfected infants. ${ }^{(8,19)}$ Thus, false-positive results can occur presumably because of the detection of nonviable nucleic acid sequences from the mother. Similarly, false-negative results can also occur depending on the primer pair, ${ }^{(18)}$ and also specimen preparation. Lack of amplifiable DNA is one specimen preparation parameter that can be controlled for by running the sample in parallel with a primer pair that amplifies a conserved region of human leukocyte antigen (HLA)-DQ $\alpha{ }^{(14)}$

Only limited data are available regarding the concordance of HIV-1 PCR and HIV-1 culture, which in an earlier published study was shown to be $88 \% .{ }^{(21)}$ Recently, two extensive studies, ACTG Protocol 076 and the Women and Infants Transmission Study (WITS), have looked at the agreement of PCR and culture. As with other reports, the concordance rate in these studies varied with time of sampling; however, by 6 months of age, the concordance

TABLE 1 Qualitative DNA PCR QA Results

\begin{tabular}{|c|c|c|c|c|c|c|}
\hline \multicolumn{4}{|c|}{ DNA cell pellets } & \multicolumn{3}{|c|}{ Whole blood specimens } \\
\hline $\begin{array}{c}\text { copy } \\
\text { number }\end{array}$ & negative & positive & $\begin{array}{l}\text { percent } \\
\text { positive }\end{array}$ & Correct & $\begin{array}{l}\text { positive } \\
(n)\end{array}$ & $\begin{array}{c}\text { negative } \\
(n)\end{array}$ \\
\hline 0 & 266 & 0 & 0 & number & $334 / 356$ & $92 / 92$ \\
\hline 2 & 28 & 28 & 50 & $(\%)$ & 94 & 100 \\
\hline 5 & 14 & 62 & 94 & & sensitivity & specificity \\
\hline 10 & 0 & 50 & 100 & & & \\
\hline 20 & 0 & 37 & 100 & & & \\
\hline 50 & 0 & 29 & 100 & & & \\
\hline
\end{tabular}


rate was $93 \%$ in the WITS ${ }^{(22)}$ and a similar rate has been observed in the 076 study. ${ }^{(23)}$ In the former study, there was a lack of concordance in eight samples in which positive PCR results were obtained that were unsubstantiated by culture. This discrepancy was apparently caused by laboratory contamination during specimen preparation at one site that was not the site performing the assays.

In spite of a rigorous QAP program, false-positive and false-negative results may occur; thus, when HIV-1 DNA PCR is used in clinical trials where the assay may be used as an end point or inclusion criterion, it is recommended that all positive and negative results be confirmed by subsequent testing with a second patient specimen, or with an additional diagnostic assay such as HIV-1 culture. On the basis of the above information, the Pediatric Virology Committee of the ACTG has developed a testing algorithm for determining the infection status of the infant. An infant is considered infected if two separate peripheral blood specimens are drawn and one is positive by culture and the other is either positive by culture or DNA PCR, or by neutralizable p24 antigen (infants $>28$ days of age). The diagnosis of lack of infection is based on the same algorithm but recognizing that false-negative results can occur at a younger age. Thus, the first "negative" specimen must be drawn when the infant is $>4$ weeks of age, and a second negative specimen should be obtained at 24 weeks of age, with both specimens drawn at least 4 weeks apart. It is important to note, in pediatric diagnosis of infection, that whereas DNA PCR may offer advantages in terms of cost and turnaround time, it is not, apparently, more sensitive than culture. The limiting factor, in terms of infant diagnosis regarding sensitivity, is probably in utero versus postpartum infection, with the former yielding an earlier diagnosis either by DNA PCR or culture than the latter.

\section{QUANTITATIVE DNA PCR \\ Quality Assurance}

Quantitative DNA PCR has not been used extensively to date in many clinical trials because quantitative plasma HIV-1 RNA levels are thought to reflect the replicating pool of HIV-1 better. Where it has been used, several approaches have been taken: serial dilution of the cells prior to extraction; ${ }^{(24,25)}$ serial dilution of the extracted DNA; ${ }^{(26,27)}$ and determination of copy number per standardized concentration of DNA based on a known quantity of PBMCs. ${ }^{(28,29)}$

Prior to consideration for implementation into clinical trials, a feasibility study to ascertain the level of agreement between laboratories was conducted by three ACTG laboratories that were performing quantitative DNA PCR using a fivefold cell dilution technique. All laboratories used the same basic procedures and the Roche Amplicor kit for detection. The laboratories were sent 12 coded, spiked cell pellet samples, six cell pellets spiked with known copy numbers $(0,2,5,10,20,50)$ as standards, and samples from four patients at three different time periods.

Although the numbers are small $(n=6)$, the reproducibilty of this assay compares well with that obtained for the qualitative DNA PCR assay. However, in assigning an absolute copy number, two of the laboratories had $92 \%$ agreement within one dilution on both the spiked cell pellets and the 12 patient samples. The third laboratory was only in agreement $25 \%$ of the time (data not shown). Although the sensitivity of the assay at 10 copy numbers is acceptable, the ability of the assay to detect changes in viral load caused by therapy is compromised by the high coefficient of variation. Table $2 \mathrm{com}$ pares the results from the two baseline samples for the same patient assayed 
by three different laboratories and illustrates that changes of $50-100 \%$ are within the variability of the assay.

\section{Clinical Usage}

Increases in proviral DNA have been associated with progression to disease, decline of CD4-positive cell count, and increased infectious viral load; ${ }^{(29-31)}$ however, it is not clear, with the drugs tested to date, that therapy-induced changes in the proviral load associated with PBMCs is in any way clinically significant. ${ }^{(26-28)}$ Thus this assay has not been implemented at multiple sites for use in clinical trials, and no further efforts have been taken for quality assurance.

\section{QUANTITATIVE RNA DETECTION Quality Assurance}

A number of assays have been developed recently using PCR or branched DNA signal amplification (bDNA) to measure HIV-1 RNA in the plasma of infected individuals. ${ }^{(32-35)}$ Preliminary studies suggest that these assays will probably be useful in monitoring viral load in clinical trials. ${ }^{(36-40)}$ Recently, a multicenter evaluation of six methods by nine sites was undertaken, ${ }^{(41)}$ demonstrating that several of the procedures could determine a fourfold change in viral load as significant. Based on analysis from this study, the ACTG is in the process of developing a QAP designed to ascertain a laboratory's capability to detect a fivefold change in RNA copy number with a probability of 0.90 . The QAP that has been developed assumes an intra-assay standard deviation of $\leqslant 0.15 \log _{10}$ RNA copies per milliliter. Whereas the initial assumption of the program is that relative change is more important than absolute numbers, use of a common set of standards and controls for each run may provide a mechanism to normalize values from different assay formats. The QAP consists of a common set of standards and controls for every run, and proficiency testing. Proficiency testing and initial laboratory certification are based on laboratory performance of a panel composed of 15 coded samples of spiked plasma containing 2,000, 10,000,50,000, 250,000, and 1,250,000 HIV-1 copies per milliliter and 9 coded patient samples prepared from an HIV-1-infected patient supplied as three fivefold dilutions in triplicate. This panel and all subsequent testing are performed using a known set of QAP standards and controls in addition to the commercial kit standards and controls. The use of a common set of standards allows for the comparison of multiple assay formats. The QAP standards are composed of supernatant fluid obtained from coculturing the PBMCs from an HIV-1-infected patient

TABLE 2 Quantitative DNA PCR Feasibility Study

\begin{tabular}{|c|c|c|c|c|c|c|c|}
\hline \multicolumn{4}{|c|}{ DNA cell pellets } & \multicolumn{4}{|c|}{ Duplicate patient PBMC samples at baseline } \\
\hline $\begin{array}{c}\text { copy } \\
\text { number }\end{array}$ & negative & positive & $\begin{array}{l}\text { percent } \\
\text { positive }\end{array}$ & patient & mean $^{\mathrm{a}}$ & S.D. & $\begin{array}{c}C V \\
(\%)^{b}\end{array}$ \\
\hline 0 & 6 & 0 & 0 & A & 225 & 234 & 104.23 \\
\hline 2 & 4 & 2 & 67 & B & 375 & 250 & 66.67 \\
\hline 5 & 1 & 5 & 83 & $\mathrm{C}$ & 2500 & 1082 & 43.30 \\
\hline 10 & 0 & 6 & 100 & $\mathrm{D}$ & 1875 & 1250 & 66.67 \\
\hline 20 & 0 & 6 & 100 & & & & \\
\hline 50 & 0 & 6 & 100 & & & & \\
\hline
\end{tabular}

${ }^{\mathrm{a}}$ Mean for all three laboratories expressed in DNA copies $/ 10^{6} \mathrm{PBMC}$.

${ }^{b}$ Coefficient of variation. 
with seronegative donor PBMCs which is then diluted into anti-HIV-1 negative human plasma as described previously. ${ }^{(41)}$

Nine laboratories participated in the initial proficiency testing panel with one laboratory using two assay formats. Four of the laboratories used the Chiron bDNA assay (Emeryville, CA), two used the Roche Molecular Systems RT-PCR assay (Branchburg, NJ), and three used in-house RNA PCR assays. Preliminary results from six of the laboratories using the commercial assays gave an interlaboratory coefficient of variation for all the mean copy numbers obtained ranging from $0 \%$ to $\sim 25 \%$ based on a comparison of all the laboratory assays' means. For any individual laboratory, the standard deviation was below the targeted value of $0.15 \log _{10}$ RNA copies per milliliter. All laboratories were able to detect a fivefold difference in copy number; however, the variation associated with the absolute value of an assay for any given copy number, in any given laboratory, has yet to be determined.

\section{Clinical Usage}

The quantitative plasma RNA detection assays are beginning to be utilized in phase I/II clinical trials to demonstrate antiretroviral activity. Previous reports have shown a decrease in the plasma RNA levels pre- and postantiretroviral therapy, ${ }^{(37)}$ with no change in plasma RNA load in patients either untreated or receiving long-term zidovudine therapy. ${ }^{(40)}$ However, patients who had received prior zidovudine therapy and were switched to combination therapy with didanosine were more likely to have a reduction in plasma RNA load than those patients who remained on zidovudine. Higher levels of plasma RNA have been shown to be associated with disease progression. ${ }^{(42-44)}$ The relationship between changes in plasma RNA load and clinical outcome presently is under investigation in two ACTG trials and one study sponsored by the Veterans Administration (VA). The standards and controls described above have been used in both of these ACTG studies, where results were obtained using the Chiron bDNA assay and the Roche Molecular Systems RT PCR assay. In one ACTG study involving late-stage patients who had prior nucleoside experience, a decrease in plasma RNA was associated with clinical benefit after controlling for other variables associated with disease progression. ${ }^{(44)}$ In the VA study of antiretroviral naive patients with less advanced disease, there also appeared to be an association of decrease in plasma RNA load 4 months after therapy that was associated with clinical benefit; however, other variables were not taken into consideration. ${ }^{(43)}$ Although the importance of these findings in other patient populations needs to be determined, this assay undoubtedly will be used extensively in clinical trials designed to measure the efficacy of antiviral agents. It should be noted that the assays, as presently designed, measure infectious and noninfectious genomic HIV-1 RNA. Thus, different antiviral agents with different modes of action may impact to a greater or lesser extent on this measurement of viral activity.

\section{SUMMARY}

Qualitative and quantitative HIV-1 DNA and RNA PCR assays are proving to be useful in the diagnosis of HIV-1 infection in infants and in assessing the in vivo antiviral activity of new therapies and regimens in clinical trials. The use of these standardized commercial assays in conjunction with an external quality assurance program has ensured that results from different laboratories are comparable. In addition, real-time proficiency monitoring has the potential to detect problems immediately before patient data are compromised.

\section{ACKNOWLEDGMENTS}

We acknowledge the contributions of the various ACTG Virology PCR Com- 
mittees, the ACTG laboratories, virologists, and technical staff who contributed to this work; the Virology QAP contractors at the Baylor College of Medicine (1987-1993; NO1-AI-82517) and Rush-Presbyterian St. Luke's Medical Center (1993-present; NO1-AI-35172); and Daniella Livnat for manuscript review.

\section{REFERENCES}

1. Jackson, J.B. and H.H. Balfour. 1988. Practical diagnostic testing for human immunodeficiency virus. Clin. Microbiol. Rev. 1: 124-138.

2. Hammer, S., C. Crumpacker, R. D'Aquila, B. Jackson, J. Lathey, D. Livnat, and P. Reichelderfer. 1993. Use of virologic assays for detection of human immunodeficiency virus in clinical trials: Recommendations of the AIDS clinical trials group virology committee. J. Clin. Microbiol. 31: 2557-2564.

3. Coombs, R.W. 1994. HIV-1 burden as a marker of disease progression and clinical response to therapy in AIDS. Clin. Lab. Med. 14: 301-311.

4. Hollinger, F.B., J.W. Bremer, L.E. Myers, J.W.M. Gold, L. McQuay, and the NIH/NIAID/DAIDS/ ACTG Virology Laboratories. 1992. Standardization of sensitive human immunodeficiency virus coculture procedures and establishment of a multicenter quality assurance program for the AIDS Clinical Trials Group. J. Clin. Microbiol. 30: 1787-1794.

5. Jackson, J.B., J. Drew, H.J. Lin, P. Otto, J.W. Bremer, F.B. Hollinger, S.M. Wolinsky, the ACTG PCR Working Group, and the ACTG PCR Virology Laboratories. 1993. Establishment of a quality assurance program for human immunodeficiency virus type 1 DNA polymerase chain reaction assays by the AIDS Clinical Trials Group. J. Clin. Microbiol. 31: 3123-3128.

6. European Collaborative Study Group. 1988. Mother-to-child transmission of HIV infection. Lancet 2: 1039-1043.

7. Comeau, A.M., H.-W. Hsu, M. Schwerzler, G.Mushinsky, and G.F. Grady. 1992. Detection of HIV in specimens from newborn screening programs. N. Engl. J. Med. 326: 1703.

8. De Rossi, A.D., L. Ometto, F. Mammano, C. Zanotto, C. Giaquinto, and L. Chieco-Bianchi. 1992. Vertical transmission of HIV-1: Lack of detectable virus in peripheral blood cells of infected children at birth. AIDS 6: 1117-1120.

9. Krivine, A., G. Firtion, L. Cao, C. Francoual, R. Henrion, and P. Lebon. 1992. HIV replication during the first weeks of life. Lancet 339: 1187-1189.

10. Busch, M.P., D.R. Henrard, I.K. Hewlett, W.F. Mehaffey, J.S. Epstein, J.-P. Allain, T.-H. Lee, J.W. Mosley, and the Transfusion Safety Study Group. 1992. Poor sensitivity, specificity, and reproducibility of detection of HIV-1 DNA in serum by polymerase chain reaction. J. Acquired Immune Defic. Syndr. 5: 872-877.

11. Defer, C., H. Agut, A. Garbarg-Chenon, M. Moncany, F. Morinet, D. Vignon, M. Mariotti, and J.J. Lefrere. 1992. Multicentre quality control of polymerase chain reaction for detection of HIV DNA. AIDS 6: 659-663.

12. Muul, L.M. and G. Milman. 1990. Polymerase chain reaction (PCR) standardization program. J. Cell Biochem. 108: S14D.

13. Sheppard, H.W., M.S. Ascher, M.P. Busch, P.R. Sohmer, M. Stanley, M.C. Luce, J.A. Chimera, R. Madej, G.C. Rodgers, C. Lynch, H. Khayam-Bashi, E.L. Murphy, B. Eble, W.Z. Bradford, R.A. Royce, and W. Winlestein Jr. 1991. A multicenter proficiency trial of gene amplification (PCR) for the detection of HIV-1. J. Acquired Immune Defic. Syndr. 4: 277-283.

14. Jackson, J.B. 1993. Detection and quantitation of human immunodeficiency virus type 1 using molecular DNA/RNA technology. Arch. Pathol. Lab. Med. 117: 473-477.

15. Kwok, S. and R. Higushi. 1989. Avoiding false-positive with PCR. Nature 339: 237-238.

16. Longo, M.C., M.S. Berninger, and J.L. Hartley. 1990. Use of uracil DNA glycosylase to control carry-over contamination in polymerase chain reaction. Gene 93: 125-128.

17. Abbott, L.Z., T. Spicer, V. Bryz-Gornia, S. Kwok, J. Sninsky, and B. Poiesz. 1994. Design and use of signature primers to detect carry-over of amplified material. J. Virol. Methods 46: 5159.

18. Brandt, C.D., T.A. Rakusan, A.V. Sison, S.H. Josephs, E.S. Saxena, K.D. Herzog, R.H. Parrott, and J.L. Sever. 1992. Detection of human immunodeficiency virus type 1 infection in young pediatric patients by using polymerase chain reaction and biotinylated probes. J. Clin. Microbiol. 30: $36-40$.

19. Borkowsky, W., K. Krasinski, H. Pollack, W. Hoover, A. Kaul, and T. Ilmet-Moore. 1992. Early diagnosis of human immunodeficiency virus infection in children $<6$ months of age: Comparison of polymerase chain reaction, culture and plasma antigen capture techniques. $J$. Infect. Dis. 166: 616-619.

20. Comeau, A.M., J.-A. Harris, K. McIntosh, B.J. Weiblen, R. Hoff, and G.F. Grady. 1992. Polymerase chain reaction in detecting HIV infection among seropositive infants: Relation to clinical status and age and to results of other assays. J. Acquired Immune Defic. Syndr. 5: 271278. 
21. Weintrub, P.S., P.P. Ulrich, J.R. Edwards, F. Boucher, J.A. Levy, M.J. Cowan, and G.N. Vyas. 1991. Use of polymerase chain reaction for the early detection of HIV infection in the infants of HIV-seropositive women. AIDS 5: 881-884.

22. Bremer, J.W., J. Carrington, E. Cooper, G. Hilyer, R. Hoff, H. Mendez, J. Moye, J. Pitt, and K. Rich. 1994. Early diagnosis of HIV infection by the Roche HIV DNA Amplicor PCR assay in infants enrolled in the Women and Infants Transmission Study (WITS). Tenth International Conference on AIDS, Yokohama, Japan. Abstract no. 266B.

23. Coombs, R.W. (pers. comm.).

24. Schnittman, S.M., J.J. Greenhouse, C. Miltiades, C. Psallidopoulos, M. Baseler, N. P. Salzman, A.S. Fauci, and H.C. Lane. 1990. Increasing viral burden in CD4 + T cells from patients with human immunodeficiency virus (HIV) infection reflects rapidly progressive immunosuppression and clinical disease. Ann. Intern. Med. 113: 438-443.

25. Simmonds, P., P. Balfe, J.F. Peutherer, C.A. Ludlam, J.O. Bishop, and A.J. Leigh-Brown. 1990. Hhuman immunodeficiency virus-infected individuals contain provirus in small numbers of peripheral mononuclear cells and at low copy numbers. J. Virol. 64: 864-872.

26. Dickover, R.E., R.M. Donovan, E. Goldstein, S.H. Cohen, V. Bolton, R.G. Huth, G. Liu, and J.R. Carlson. 1992. Decreases in unintegrated HIV DNA are associated with antiretroviral therapy in AIDS patients. J. Acquired Immune Defic. Syndr. 5: 31-35.

27. Clark, A.G.B., M. Holodniy, D.H. Schwartz, D.A. Katzenstein, and T.C. Merigan. 1992. Decreases in HIV provirus in peripheral blood mononuclear cells during zidovudine and human rIL-2 administration. J. Acquired Immune Defic. Syndr. 5: 52-59.

28. Montoya, J.G., R. Wood, D. Katzenstein, M. Holodniy, and T. Merigan. 1993. Peripheral blood mononuclear cell human immunodeficiency virus type 1 proviral DNA quantification by the polymerase chain reaction: Relationship to immunodeficiency and drug effect. J. Clin. Microbiol. 31: 2692-2696.

29. Yerly, S., E. Chamot, B. Hirschel, and L.H. Perrin. 1992. Quantitation of human immunodeficiency provirus and circulating virus: Relationship with immunologic parameters. $J$. Infect. Dis. 166: 269-276.

30. Bieniasz, P.D., K. Ariyoshi, M.A.D. Bourelly, S. Bloor, R.B. Foxall, E.C. Harwood, and J.N. Weber. 1993. Variable relationship between proviral DNA load and infectious virus titer in the peripheral blood mononuclear cells of HIV-1-infected individuals. AIDS 7: 803-806.

31. Urdea, M.S. 1993. Synthesis and characterization of branched DNA (bDNA) for the direct and quantitative detection of CMV, HBV, and HIV. Clin. Chem. 36: 725-726.

32. Coombs, R.W., D.R. Henrard, W.F. Mehaffey, J. Gibson, E. Eggert, T.C. Quinn, and J. Phillips. 1993. Cell-free plasma human immunodeficiency virus type 1 titer assessed by culture and immunocapture-reverse transcription-polymerase chain reaction. J. Clin. Microbiol. 31: 1980-1986.

33. Holodniy, M., D.A. Katzenstein, and S. Sengupta. 1991. Detection and quantification of human immunodeficiency virus RNA in patient serum by use of the polymerase chain reaction. J. Infect. Dis. 163: 862-866.

34. Piatak, M., M.S. Saag, and L.C. Yang. 1993. High levels of HIV-1 in plasma during all stages of infection determined by competitive PCR. Science 259: 1749-1754.

35. Mulder, J., N. McKinney, C. Christopherson, J. Sninsky, L. Greenfield, and S. Kwok. 1994. Rapid and simple PCR assay for quantitation of human immunodeficiency virus type 1 RNA in plasma: Application to acute retroviral infection. J. Clin. Microbiol. 32: 292-300.

36. Semple, M., C. Loveday, I. Weller, and R. Tedder. 1991. Direct measurement of viraemia in patients infected with HIV-1 and its relationship to disease progression and zidovudine therapy. J. Med. Virol. 35: 38-45.

37. Holodniy M., D.A. Katzenstein, D.M. Israelski, and T.C. Merigan. 1991. Reduction in plasma human immunodeficiency virus ribonucleic acid after dideoxynucleoside therapy as determined by the polymerase chain reaction. J. Clin. Invest. 88: 1755-1759.

38. Aoki-sei, S., R.Y. Yarchoan, S. Kageyama, D.T. Hoekzema, J.M. Pluda, K.M. Wyvill, S. Broder, and H. Mitsuya. 1992. Plasma HIV-1 viremia in HIV-1 infected individuals assessed by polymerase chain reaction. AIDS Res. Hum. Retroviruses 8: 1263-1270.

39. Colier, A.C., R.W. Coombs, M.A. Fischl, P.R. Skolnik, D. Northfeldt, P. Boutin, C.J. Hooper, L.D. Kaplan, P.A. Volberding, L.G. Davis, D.R. Henrard, S. Weller, and L. Corey. 1993. Combination therapy with zidovudine and didanosine compared to zidovudine alone in human immunodeficiency virus type one infection. Ann. Intern. Med. 119: 786-793.

40. Winters, M.A., L.B. Tan, D.A. Katzenstein, and T.C. Merigan. 1993. Biological variation and quality control of plasma human immunodeficiency virus type 1 RNA quantitation by reverse transcriptase-polymerase chain reaction. J. Clin. Microbiol. 31: 2960-2966.

41. Lin, H.J., L.E. Myers, B. Yen-Lieberman, F.B. Hollinger, D. Henrard, C.J. Hooper, R. Kokka, S. Kwok, S. Rasheed, M. Vahey, M.A. Winters, L.J. McQuay, P.L. Nara, P. Reichelderfer, R.W. Coombs, and J.B. Jackson. 1994. Multicenter evaluation of methods for the quantitation of plasma HIV-1 RNA. J. Infect. Dis. 170: 553-562.

42. Vahey, M.T., D.L. Mayers, K.F. Wagner, R.C.Y. Chung, O.S. Weislow, S. Zhou, D.S. Burke, and RV43 Study Group. 1994. Plasma HIV RNA predicts clinical outcome on AZT therapy. Tenth 
International Conference on AIDS, Yokohama, Japan. Abstract no. 253B.

43. O'Brien, W.A., P.M. Hartigan, B. McCreedy, and J.D. Hamilton. 1994. Plasma HIV RNA and $b_{2}$ microglobin as surrogate markers. Tenth International Conference on AIDS, Yokohama, Japan. Abstract no. 254B.

44. Hooper, C., S. Welles, R. D'Aquila, A. Japour, V. Johnson, D. Kuritzkes, B. Jackson, V. DeGruttola, C. Crumpacker, D. Richman, J. Kahn, S. Kwok, J. Todd, P. Reichelderfer, and R. Coombs. 1994. HIV-1 RNA level in plasma and association with disease progression, zidovudine sensitivity phenotype and genotype, syncytium-inducing phenotype, CD4 + cell count and clinical diagnosis of AIDS, p. 67. Third International Workshop on Drug Resistance. Kauai, Hawaii. 


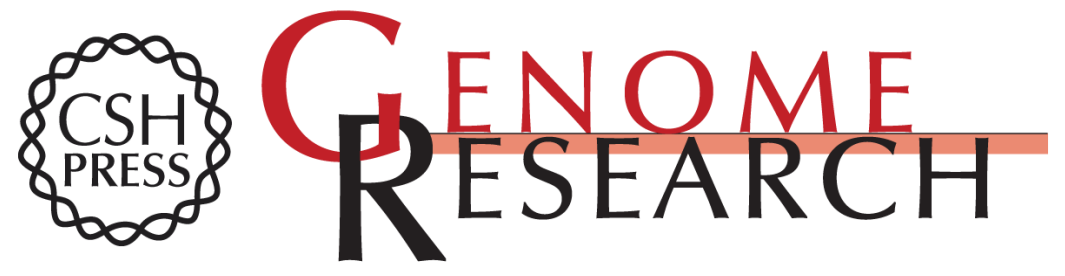

\section{Quality assurance and use of PCR in clinical trials.}

P S Reichelderfer and J B Jackson

Genome Res. 1994 4: S141-S149

References This article cites 39 articles, 11 of which can be accessed free at:

http://genome.cshlp.org/content/4/3/S141.full.html\#ref-list-1

\section{License}

Email Alerting Receive free email alerts when new articles cite this article - sign up in the box at the Service top right corner of the article or click here.

\section{Affordable, Accurate Sequencing.}

To subscribe to Genome Research go to: https://genome.cshlp.org/subscriptions 